\title{
Correction to: Palmar fasciitis and polyarthritis: an uncommon but remarkable paraneoplastic syndrome
}

\author{
Hannelore Celen ${ }^{1}$ (D) Barbara Neerinckx ${ }^{1,2}$ \\ Published online: 8 February 2021 \\ (C) International League of Associations for Rheumatology (ILAR) 2021
}

\section{Correction to: Clinical Rheumatology https://doi.org/10.1007/s10067-020-05552-z}

The Cover letter and Reviewers' comments for the original manuscript prior publication of the above article should have been deleted in the published version. The original article has been corrected.

Publisher's note Springer Nature remains neutral with regard to jurisdictional claims in published maps and institutional affiliations.

The online version of the original article can be found at https://doi.org/ $10.1007 / \mathrm{s} 10067-020-05552-\mathrm{Z}$

Hannelore Celen

hannelore.celen@uzleuven.be

1 Division of Rheumatology, University Hospitals Leuven, Herestraat 49, 3000 Leuven, Belgium

2 Skeletal Biology and Engineering Research Centre, Department of Development and Regeneration, KU Leuven, Leuven, Belgium 